Section Editor

Robert C. Griggs, MD
Editors' Note: In the study by Broeders et al. concerning cognitive impairment in Parkinson disease (PD), 2 different groups report their own experiences. Kano et al. propose that patients with rigidity-dominant PD may be more susceptible to developing cognitive impairment than those in the tremor-dominant group. The need to provide more specific inclusion and exclusion criteria and the need to use specific tests are Dr. Dyck's main concerns regarding the Dutch survey on small-fiber neuropathy.

-Chafic Karam, MD, and Robert C. Griggs, $M D$

\section{EVOLUTION OF MILD COGNITIVE IMPAIRMENT IN PARKINSON DISEASE}

Marina Picillo, Naples and Salerno; Paolo Barone, Maria Teresa Pellecchia, Salerno; Gabriella Santangelo, Caserta, Italy: Broeders et al. ${ }^{1}$ reported on the evolution of mild cognitive impairment (MCI) in patients with de novo Parkinson disease (PD). We reported the prevalence of PD-MCI and its 2-year development in our study population. ${ }^{2,3}$ Seventynine de novo, drug-naive parkinsonian patients were enrolled. Diagnosis was checked twice during the course of the study and 3 patients were excluded due to a revised diagnosis. Two years later, 61 patients participated in follow-up. According to recent criteria, ${ }^{4}$ PD-MCI occurred in $28 / 76$ patients $(36.8 \%)$ at baseline and in 26/61 patients (42.6\%) at follow-up. According to PD dementia (PDD) criteria, ${ }^{5}$ none of the patients showed PDD. At baseline and 2-year follow-up, patients with MCI had lower MiniMental State Examination (MMSE) score (26.4 [2.1] vs 27.8 [1.6], $p=0.004$, and 27 [2.5] vs 28 [1], $p=0.04$, respectively) but not higher motor scores (Unified Parkinson's Disease Rating Scale [UPDRS]-III, Hoehn \& Yahr) and mood symptoms (Hosptial Anxiety and Depression Scale) than patients without PD-MCI. Compared to the study by Broeders et al., we found a lower percentage of PD-MCI at 2-year follow-up and no PDD. Furthermore, our patients with PD-MCI did not present with higher motor and mood scores than patients without PD-MCI. We speculate that these discrepancies could be due to the younger age at onset of our cohort (58.5 [8.3] vs 66.1 [10.1] years).
Osamu Kano, Ken Ikeda, Yasuo Iwasaki, Tokyo: Broeders et al. ${ }^{1}$ reported a group of new patients diagnosed with PD. About one-third of these patients fulfilled the criteria for PD-MCI at the time of diagnosis. After 5 years, approximately $50 \%$ of the patients were without dementia. We studied cognitive function in patients with PD and analyzed the relationship between cognitive function and motor symptoms in PD. ${ }^{6}$ We assessed cognitive function by using the MMSE. The patients performed poorly on the MMSE, which suggests a relationship between severity of rigidity and memory impairments. Broeders et al. reported that patients with $\mathrm{PD}$ were evaluated using the UPDRS. We would like to know which part was used. We think that patients in the rigidity-dominant group are more susceptible to developing cognitive impairment than those in the tremor-dominant group. However, it was not clear from this study whether there was any relationship between cognitive impairment and parkinsonian symptoms.

(C) 2014 American Academy of Neurology

1. Broeders M, de Bie RM, Velseboer DC, et al. Evolution of mild cognitive impairment in Parkinson disease. Neurology 2013;81:346-352.

2. Aarsland D, Bronnick K, Williams-Gray C, et al. Mild cognitive impairment in Parkinson disease: a multicenter pooled analysis. Neurology 2010;75:1062-1069.

3. Pellecchia MT, Santangelo G, Picillo M, et al. Serum epidermal growth factor predicts cognitive functions in early, drug-naive Parkinson's disease patients. J Neurol 2013;260: 438-444.

4. Litvan I, Goldman JG, Tröster AI, et al. Diagnostic criteria for mild cognitive impairment in Parkinson's disease: movement disorder society task force guidelines. Mov Disord 2012;27:349-356.

5. Emre M, Aarsland D, Brown R, et al. Clinical diagnostic criteria for dementia associated with Parkinson's disease. Mov Disord 2007;22:1689-1707.

6. Iwasaki Y, Kinoshita M, Ikeda K, Takamiya K. Cognitive function in Parkinson's disease: in relation to motor symptoms. Int J Neurosci 1989;47:295-300.

\section{RISK FACTORS FOR DEMENTIA WITH LEWY BODIES: A CASE-CONTROL STUDY}

Angel Golimstok, Buenos Aires: Boot et al. ${ }^{1}$ studied several risk factors for dementia with Lewy bodies (DLB). We reported that the history of attention- 


\section{Neurology}

\section{Evolution of mild cognitive impairment in Parkinson disease}

Marina Picillo, Osamu Kano, Paolo Barone, et al.

Neurology 2014;82;1384

DOI 10.1212/WNL.0000000000000234

\section{This information is current as of April 14, 2014}

\section{Updated Information \&} Services

References

Permissions \& Licensing

Reprints including high resolution figures, can be found at: http://n.neurology.org/content/82/15/1384.1.full

This article cites 6 articles, 2 of which you can access for free at: http://n.neurology.org/content/82/15/1384.1.full\#ref-list-1

Information about reproducing this article in parts (figures,tables) or in its entirety can be found online at:

http://www.neurology.org/about/about_the_journal\#permissions

Information about ordering reprints can be found online:

http://n.neurology.org/subscribers/advertise

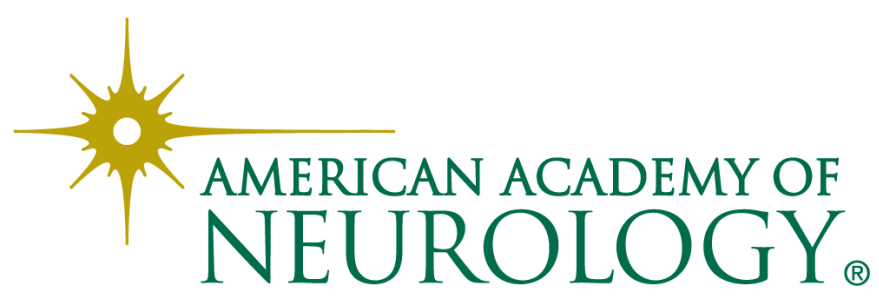

